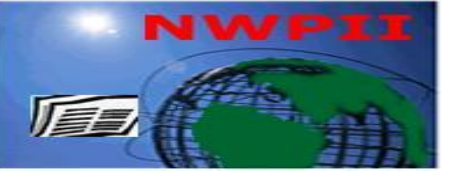

American Journal of Biomedical Sciences

ISSN: 1937-9080

nwpii.com/ajbms

\title{
Effect of Concomitant Administration of $\alpha$-tocopherol and ACEI on Cardiovascular Performance and Nucleic Acid Changes in DOCA Hypertensive Rats
}

\author{
Sohair A Saleh ${ }^{(1)}$, Sobhy S Hassab El-Nabi ${ }^{(2)}$, Mamdouh R El-Ridi ${ }^{(1)}$, Mohamed D Morsy*(1), \\ Safaa M Kotb ${ }^{(1)}$, Mohamed A Abd-Allah ${ }^{(1)}$ \\ ${ }^{1}$ Physiology Department, College of Medicine, Menoufiya University, Egypt. \\ ${ }^{2}$ Genetics and Molecular Biology Department, College of Science, Menoufiya University, Egypt. \\ *Corresponding Author: \\ Mohamed D. Morsy \\ Associate professor of \\ Physiology Department, College of Medicine \\ Menoufiya University \\ Shibeen Alkoom, Egypt \\ Mobile: +966-544495223 \\ Tel: +966-72298311 \\ E-mail: morsydarwesh@yahoo.com
}

Received: 5 August 2010; | Revised: 11 October 2010; | Accepted: 14 November 2010

\section{Abstract}

Background: Evidence for cardiovascular oxidative stress in animals with hypertension has been accumulated. Antioxidant agents have been used to treat endothelial dysfunction and arterial hypertension.

Aim: The aim of present study is to elucidate the effect of concomitant administration of $\alpha$-tocopherol (antioxidant) and angiotensin converting enzyme inhibitor (ACEI; anti-hyptertensive) on cardiac smooth muscle DNA and RNA changes in DOCA induced hypertension in rats.

Methods: 48 male Sprague-Dawley rats were used in this study and were divided into 6 groups $(\mathrm{n}=8)$ : C control rats; CE control rats received $\alpha$-tocopherol $(60 \mathrm{mg} / \mathrm{kg})$ intragastrically (IG); DOCA rats were made hypertensive by SC injection of DOCA $(50 \mathrm{mg} / \mathrm{kg}$ once weekly for 4 weeks); DOCA+E; DOCA hypertensive rats received $\alpha$-tocopherol (60 mg/kg) IG; DOCA+ACEI; DOCA hypertensive rats received ACEI (captopril; $15 \mathrm{mg} / \mathrm{kg}$ ) IG; and DOCA+E+ACEI; DOCA hypertensive rats received both $\alpha$-tocopherol and captopril in the same doses as DOCA+E and DOCA+ACEI groups respectively. All IG treatments were given to the animals 6 days weekly for 6 weeks. At the end of experimental protocol, systolic blood pressure (MSP), renal vascular flow velocity (RFV), renal vascular resistance (RVR), myocardial contractility (MC) and heart rate (HR) were measured in rats of all groups. Also, serum sodium $\left(\mathrm{Na}^{+}\right)$, potassium $\left(\mathrm{K}^{+}\right)$and total plasma antioxidant capacity (TOC) were measured. DNA and RNA analysis were done for the myocardial tissue homogenate.

Results: While DOCA administration in rats produced significant increase in serum $\mathrm{Na}^{+}, \mathrm{MSP}, \mathrm{RVR}$, and RNA levels; it reduced significantly serum $\mathrm{K}^{+}, \mathrm{TOC}, \mathrm{MC}$ and DNA levels compared with the control group. Concomitant administration of both $\alpha$-tocopherol and ACEI resulted in significant reduction of serum $\mathrm{Na}^{+}$, 
MSP, RVR, and RNA levels and significant elevation of serum $\mathrm{K}^{+}$, TOC, MC and DNA levels compared with either $\alpha$-tocopherol or ACEI treatment in DOCA rats.

Conclusions: Concomitant administration of both $\alpha$-tocopherol and ACEI reduces the risk of the development of myocardial DNA, RNA and nuclear changes associated with DOCA induced hypertension. This could make a promising addition mechanism of action of $\alpha$-tocopherol that confirms its therapeutic uses in the treatment of hypertension in human.

Keywords: DOCA, Hypertension, ACEI, DNA, RNA, total antioxidant capacity, $\alpha$-tocopherol.

\section{Introduction}

Hypertension is a major risk factor for cardiovascular morbidity and mortality which is known to be affected by genetic and heritable factors [1]. Ventricular hypertrophy, one of the cardiac complications, has been considered as a compensatory mechanism to an increased vascular resistance. However, it could also reflect a primary response to repeated neural stimulation and, thereby, could be an initiating mechanism for hypertension [2]; as well an amplifier of cardiac output that reinforces the elevation of blood pressure upstream from the constricted arteriolar bed [1]. Vascular complications include increasing wall thickness to lumen radius, remodeling, largevessel hypertrophy and endothelial dysfunction has been reported [3]. Several arguments have been suggested that; hypertension can be considered, at least in part, as a vascular proliferative disorder. Hyperplasia is observed in vitro in vascular smooth muscle cells and fibroblasts from genetically hypertensive rats [4]. Several studies have described neonatal cardiac hypertrophy in vivo and others reported that the kidneys, the heart and the aorta of genetically hypertensive rats have an increased amount of DNA which incorporates elevated quantities of thymidine. This persistence of hyperplasia in vitro and its presence in neonates indicate that hyperplasia is not simply due to heightened blood pressure but can indeed constitute a precipitating element [5].

A primary cause of chronic vascular disease progression is increased oxidative stress in the endothelium caused by multiple risk factor conditions, including dyslipidemia, smoking, diabetes, neurogenic elevation of systolic blood pressure and genetic background [6]. Oxidative stress may contribute to the pathogenesis of

Am. J. Biomed. Sci. 2011, 3(1), 57-68; doi: 10.5099/aj110100058 hypertension and endothelial dysfunction via increased production of free radicals in the arterial wall [7]. Free radicals play an important role as mediators of cardiac and vascular smooth muscle damage and inflammation. It is generally accepted that tonic release of NO from the endothelium exerts vasculoprotective and cardioprotective effects; and its reduction enhances apoptosis of endothelial cells [8]. Peroxynitrite (the product results from interaction of superoxide overproduction with NO) overproduction may induce DNA single strand breaks, which may contribute to the endothelial oxidative stress damage [9]. High concentrations of peroxynitrite trigger rapid derangements in energy metabolism and poly (ADP-ribose) polymerase (PARP-1) activation leading to cellular necrosis. Oxidative DNA damage may lead to the activation of the nuclear enzyme PARP-1, which can trigger a cellular suicide pathway [10]. Also, it has been reported that, reactive oxygen and nitrogen species contributes to cardiovascular DNA damage in hypertensive rats [11].

To prevent or delay oxidation, several antioxidants including $\alpha$-tocopherol are used for treatment of cardiovascular diseases, cancer, chronic inflammation, Alzheimer disease, and Parkinson disease [12]. Antioxidants reduce oxidative stress and high blood pressure levels, and improve vascular function. Epidemiological studies suggest that $\alpha$-tocopherol could improve redox-sensitive vascular changes associated with hypertension [13]. Accordingly, we can suggest that, $\alpha$-tocopherol being one of the most powerful antioxidants could protect against oxidativesensitive DNA vascular changes with subsequent hypertension.

The aim of the present study is to elucidate the effect of concomitant administration of both oral $\alpha$ tocopherol and ACEI on DOCA induced DNA, 
RNA and nucleic acid changes in cardiac smooth muscle cells in DOCA induced hypertension in rats.

\section{Methods}

All animals received human care in compliance with the Public Health Service Policy on Human Care and Use of Laboratory Animals published by the National Institutes of Health and was approved by the Ethical Committee of the College of Medicine, Menoufiya University, Egypt.

\subsection{Experimental animals}

This study was carried out on 48 male Sprague-Dawley rats (150 -200 g). Animals were fed with standard laboratory chow and water ad libitum and housed in the animal house of Menoufiya College of Medicine under artificial light/dark cycle of $12 \mathrm{~h}$. The animals were divided into 6 groups $(\mathrm{n}=8$ each): $\mathrm{C}$ rats had no hypertension but were subcutaneously (SC) injected with $0.3 \mathrm{~mL}$ olive oil (vehicle) once weekly for 4 weeks. Concomitantly, they were fed intragastrically (IG) with olive oil $(0.1 \mathrm{~mL} / 100 \mathrm{~g}$ body weight); $\mathrm{CE}$ animals were $\mathrm{SC}$ injected with olive oil as in $\mathrm{C}$ group and were given $\alpha$ tocopherol $(60 \mathrm{mg} / \mathrm{kg})$ dissolved in $0.1 \mathrm{~mL}$ olive oil IG; DOCA Hypertensive rats which were made hypertensive by SC injection of DOCA (deoxy corticosterone acetate) in a dose of $50 \mathrm{mg} / \mathrm{kg}$ suspended in $0.3 \mathrm{~mL}$ olive oil once weekly for 4 weeks with addition of $1 \% \mathrm{NaCl}$ to the drinking water. Rats were considered hypertensive when their systolic arterial blood pressure was maintained above $140 \mathrm{mmHg}$ [14]. They were also given olive oil IG as in $\mathrm{C}$ group; DOCA $+\mathrm{E}$ animals, where hypertensive rats were received $\alpha$ tocopherol as CE group. DOCA+ACEI where DOCA hypertensive animals were IG treated with ACEI (captopril; $15 \mathrm{mg} / \mathrm{kg}$ ) daily [15] and were given olive oil as in $\mathrm{C}$ group and DOCA + ACEI + $\mathrm{E}$ hypertensive rats, where DOCA hypertensive animals were received IG $\alpha$-tocopherol and captopril in the same doses as group DOCA+E and DOCA+ACEI respectively. All IG treatments were given 6 days weekly for 6 weeks.

Am. J. Biomed. Sci. 2011, 3(1), 57-68; doi: 10.5099/aj110100058

\subsection{Measurement of mean arterial pressure (MAP)}

At the end of the experimental protocol period (6 weeks), MAP was measured using tail-cuff plethysmography (Harvard Apparatus Ltd., England) [16] in conscious rats pre-warmed for 10 min in a thermostatically controlled restrainer (XBP1000; Kent Scientific). The mean of at least 3 separate recordings on 3 occasions was taken.

\subsection{Measurement of renal blood flow velocity (RBF) and renal vascular resistance (RVR)}

After overnight fast, the animals were anesthetized with thiopental sodium $(60 \mathrm{mg} / \mathrm{kg}$ body wt, i.p.) [17]. The trachea was intubated, the abdominal wall was opened by midline incision, the left renal artery was explored and was gently freed from surrounding tissue. The probe top of Pulsed Doppler Flow-meter (Model T206, Transonic System, and Ithaca, NY) was covered with an ultrasound gel, the volume control was adjusted to maximum and the probe was pressed gently to the measurement area of the renal artery at $45-60^{\circ}$. After hearing the optimal sounds for 5 seconds continually, the freeze key was pressed to freeze the wave form record [18].

\subsection{Heart perfusion experiment, Blood sampling}

After measuring the RBF and RVR, rats were anticoagulated with heparin (1000 IU/kg i.v.) then were sacrificed by cervical decapitation. The chest was rapidly opened and the vessels to and from the heart were clamped with 2 curved artery forceps then, cut along side of the proximal forceps edge to excise the heart and its connected blood vessels. The excised heart was immediately plunged in icecold Krebs' solution [modified krebs'-Henseleit solution] which formed of $(\mathrm{NaCl} 118 \mathrm{mM} ; \mathrm{KCl}$ $4.7 \mathrm{mM} ; \mathrm{CaCl}_{2} 2.5 \mathrm{mM}$; $\mathrm{Mg} \mathrm{SO}_{4} .7 \mathrm{H}_{2} \mathrm{O} 1.2 \mathrm{mM}$; $\mathrm{NaHCO}_{3} 25 \mathrm{mM} ; \mathrm{KH}_{2} \mathrm{PO}_{4} 1.2 \mathrm{mM}$; glucose $11 \mathrm{mM}$ per liter) with $\mathrm{pH}$ 7.4. The heart was kept in the ice-cold Krebs' for 20-50 seconds before it was mounted to the langendorff's heart perfusion apparatus. After that, the aorta was cannulated in a heart cannula for coronary perfusion and the whole procedure took about 1-1.5 minutes. The isolated heart was then perfused with the modified Krebs'Henseleit solution bubbled with $5 \% \mathrm{CO}_{2}$ in $95 \%$ $\mathrm{O}_{2}$ at a constant controlled flow rate of $4.4 \mathrm{~mL} / \mathrm{min}$ 
with maintained temperature at $37.5{ }^{\circ} \mathrm{C}$. The preparation was left for $20 \mathrm{~min}$ for equilibration. Then cardiac muscle was connected with the langendorff's heart perfusion apparatus which was connected with isometric strain gauge transducer (Myograph F-60-H. B.S. Narco BiosystemEngland-U.K.) and. A 4-channel physiograph (M.K. III-S-HBS Narco Biosystems-EnglandU.K.) was used to record the myocardiacal contractility (MC) and heart rate (HR) [19]. Immediately after exaction of the heart, aortic blood samples (each 2mL) were obtained and samples were allowed to clot and centrifuged at $14,000 \mathrm{rpm}$ for $10 \mathrm{~min}$ for serum separation to be used for determination of serum $\mathrm{Na}^{+}, \mathrm{K}^{+}$and total antioxidant activity.

\subsection{Estimation of serum Sodium and potassium}

Serum $\mathrm{Na}^{+}$and $\mathrm{K}^{+}$levels were estimated spectrophotometerically used their specific kits [20]. Both $\mathrm{Na}^{+}$and $\mathrm{K}^{+}$levels were determined in $\mathrm{mmol} / \mathrm{L}$. spectrophotometer was set to the wavelength at 500, and $550 \mathrm{~nm}$ respectively.

\subsection{Assay of Total antioxidant status}

The assay relies on the ability of antioxidants in the serum samples to inhibit the oxidation of 2 , 2'-Azino-di-[3-ethylbenzthiazoline sulphonate] (ABTS) by metmyoglobin. The amount of oxidized ABTS produced can be monitored at the absorbance of $750 \mathrm{~nm}$. Under the reaction conditions used, the antioxidants in the samples cause suppression of the absorbance at $750 \mathrm{~nm}$ to a degree which is proportional to their concentration. The capacity of the antioxidants in the sample to prevent ABTS oxidation is compared with that of Trolox; a water-soluble tocopherol analogue; and is quantified as milli molar Trolox equivalents [21].

\subsection{DNA extraction and apoptosis detection in cardiac tissue}

Gel was prepared using $1.8 \%$ electrophoretic grade agarose. The agarose was boiled with tris borate EDTA buffer (1x TBE buffer; $89 \mathrm{mM}$ Tris, $89 \mathrm{mM}$ boric acid, $2 \mathrm{mM}$ EDTA, pH 8.3) then, 0.5 microgram $/ \mathrm{mL}$ ethidium bromide was added to agarose mixture at $40{ }^{\circ} \mathrm{C}$. Gel was poured and allowed to solidify at room temperature for 1 hour before samples were loaded. Nucleic acids extraction and detection of apoptosis was done according to "salting out extraction method of "Aljanabi and Martinez [22] and modification introduced by Hassab El-Nabi [23]. Protein was precipitated by saturated solution of $\mathrm{NaCl}(5 \mathrm{M})$. $0.015 \mathrm{~g}$ of left ventricular cardiac muscle was taken in each eppendorf tube and was crushed and then lysed with 600 microlitre lysing buffer (50 $\mathrm{mM} \mathrm{NaCl}, 1 \mathrm{mM} \mathrm{Na} 2$ EDTA, 0.5\% SDS, $\mathrm{pH}$ 8.3) and gently shacked. The mixture was incubated overnight at $37^{\circ} \mathrm{C}$ then, 200 microlitre of saturated $\mathrm{NaCl}$ was added to the samples, shacked gently and centrifuged at $12,000 \mathrm{rpm}$ for $10 \mathrm{~min}$. The supernatant was transferred to new eppendorf tubes and then DNA precipitated by 600 microlitre cold isopropanol. The mixture was inverted several time till fine fibres appear, and then centrifuged for 5 $\min$ at $12,000 \mathrm{rpm}$. The supernatant is removed, and the pellets were washed with 500 micolitre $70 \%$ ethyl alcohol, centrifuged at $12,000 \mathrm{rpm}$ for 5 min. After centrifugation, the alcohol was decanted and the tubes blotted on Whatman paper, till the pellets left to dry. The pellets were resuspended in 50 microlitre or appropriate volume of TE buffer (10 mM tris, 1mM EDTA, pH 8) supplemented with 5\% glycerol. The resuspended DNA was incubated for 30 min with loading mix (Rense + loading buffer) and then loaded directly into the gel-wells. All results were analyzed using GelPro® Analyzer version 3 (Hartland, WI, U.S.A).

\subsection{Chemicals}

DOCA, $\alpha$-tocopherol and chemicals used for preparation of Krebs'-Henseleit solution were purchased from Sigma (St Louis, MO, USA). Captopril was ordered from Bristol Myers Squibb (Waltham, MA, USA). A serum total antioxidatant capacity kit was supplied by Cayman chemical USA, while serum sodium and potassium measurement kits were ordered from Teco diagnostic USA.

\subsection{Statistical analysis}

Statistical analysis was performed by Kruskal Wallis one-way ANOVA for multiple comparisons followed by Fisher's PLSD test. Values are expressed as mean \pm SD. Post-hoc Scheffe test was 
applied to identify the source of statistical significance. P-values $<0.05$ were considered statistically significant.

\section{Results}

\subsection{Changes in vascular parameters}

Table (1) and Figure (1) showed that DOCA administration in rats significantly increases MSP $(168.5 \pm 15.48 \mathrm{mmHg}), \quad H R \quad(275.88 \pm 21.72$ beat/min) and RVR of renal artery $(2.1 \pm 0.19$ PRU) while both MC $(1.63 \pm 0.15 \mathrm{~g}$ tension $)$ and RFV (4.3 $\pm 0.4 \quad \mathrm{~cm} / \mathrm{sec})$ were significantly decreased compared with the control groups (95.9 $\pm 9.3 \mathrm{mmHg}, 162.63 \pm 15.77 \mathrm{beat} / \mathrm{min}, 0.85 \pm 0.07$ PRU, $3.57 \pm 0.28 \mathrm{~g}$ tension, $6.9 \pm 0.5 \mathrm{~cm} / \mathrm{sec}$ respectively). Administration of either $\alpha$ tocopherol (60 mg/kg) or ACEI (captopril; 15 $\mathrm{mg} / \mathrm{kg}$ ) in DOCA hypertensive rats produced significant reduction of MSP $(133.7 \pm 13.19$ $\mathrm{mmHg}, 106.75 \pm 10.72 \mathrm{mmHg})$, HR (221 \pm 19.67 beat $/ \mathrm{min}, 176.75 \pm 18.21 \mathrm{beat} / \mathrm{min})$ and RVR (1.7 \pm 0.18 PRU, $1.08 \pm 0.09$ PRU) of renal artery and significantly increased MC $(2.13 \pm 0.20 \mathrm{~g}$ tension, $2.58 \pm 0.21 \mathrm{~g}$ tension $)$ and RFV $(5.1 \pm 0.3 \mathrm{~cm} / \mathrm{sec}$, $5.9 \pm 0.2 \mathrm{~cm} / \mathrm{sec}$ ) compared with the DOCA group. The results of ACEI group showed significant improvement $(\mathrm{P}<0.001)$ compared with the $\alpha$ tocopherol treated group. On the other hand, concomitant treatment with both $\alpha$-tocopherol and ACEI produced significantly $(\mathrm{P}<0.001)$ improvement of the all previous measured parameters compared with DOCA and DOCA+E and DOCA+ACEI groups except for RVR which became insignificantly changed $(\mathrm{P}>0.05)$ compared with ACEI treated group.

Table 1. Effect of vitamin E and ACEI on Systolic blood pressure (MSP), Cardiac contractility (g tension) and Heart rate (HR) and Renal blood flow velocity (RFV), Renal vascular resistance (RVR), Serum $\mathrm{Na}^{+}$and $\mathrm{K}^{+}$levels in different groups.

\begin{tabular}{|c|c|c|c|c|c|}
\hline & $\begin{array}{c}\text { DOCA } \\
+ \text { E+ACEI }\end{array}$ & DOCA +ACEI & $\mathrm{DOCA}+\mathrm{E}$ & DOCA & $\mathbf{C}$ \\
\hline $\begin{array}{c}\text { MSP } \\
(\mathbf{m m ~ H g})\end{array}$ & $104.5 \pm 10.1^{(\mathrm{d}, \mathrm{e})}$ & $106.75 \pm 10.72^{(\mathrm{d})}$ & $133.7 \pm 13.19^{(\mathrm{c})}$ & $168.5 \pm 15.48^{(b)}$ & $95.9 \pm 9.3^{(\mathrm{a})}$ \\
\hline RFV (cm/sec) & $5.7 \pm 0.3^{(\mathrm{d}, \mathrm{e})}$ & $5.9 \pm 0.2^{(\mathrm{d})}$ & $5.1 \pm 0.3^{(\mathrm{c})}$ & $4.3 \pm 0.4^{(\mathrm{b})}$ & $6.9 \pm 0.5^{(a)}$ \\
\hline RVR (PRU) & $1.1 \pm 0.10^{(\mathrm{d}, \mathrm{e})}$ & $1.08 \pm 0.09^{(\mathrm{d})}$ & $1.7 \pm 0.18^{(\mathrm{c})}$ & $2.1 \pm 0.19^{(b)}$ & $0.85 \pm 0.07^{(a)}$ \\
\hline Serum $\mathrm{Na}^{+}$ & $128.7 \pm 11.37^{(\mathrm{a}, \mathrm{e})}$ & $130.2 \pm 14.12^{(\mathrm{c}, \mathrm{d})}$ & $132.5 \pm 11.86^{(\mathrm{c})}$ & $142.85 \pm 13.67^{(\mathrm{b})}$ & $\begin{array}{l}128.3 \pm \\
12.71^{(\mathrm{a})}\end{array}$ \\
\hline Serum $K^{+}$ & $3.9 \pm 0.38^{(\mathrm{a}, \mathrm{c}, \mathrm{d}, \mathrm{e})}$ & $3.86 \pm 0.37^{(\mathrm{a}, \mathrm{c}, \mathrm{d})}$ & $3.84 \pm 0.31^{(\mathrm{a}, \mathrm{c})}$ & $2.92 \pm 0.28^{(\mathrm{b})}$ & $3.9 \pm 0.34^{(a)}$ \\
\hline
\end{tabular}

C: Control group; DOCA: Hypertensive rats; DOCA+E: Hypertensive rats treated with vitamin E; DOCA+ACEI: Hypertensive rats treated with ACEI and DOCA+E+ACEI: Hypertensive rats treated with both vitamin E and ACEI. Results are expressed as mean $\pm \mathrm{SD}(\mathrm{n}=8)$.

Groups with different letters are statistically significant $(\mathrm{p}<0.001)$

\subsection{Changes in serum $\mathrm{Na}^{+}, \mathrm{K}^{+}$and TAC}

Induction of hypertension in DOCA group of rats produced significant reduction of both serum $\mathrm{K}^{+}(2.92 \pm 0.28 \mathrm{mEq} / \mathrm{L})$ and TAC $(0.99 \pm 0.08$ $\mathrm{mmol} / \mathrm{L})$ and significant increases in serum $\mathrm{Na}^{+}$ Am. J. Biomed. Sci. 2011, 3(1), 57-68; doi: 10.5099/aj110100058 levels $(142.85 \pm 13.67 \mathrm{mEq} / \mathrm{L})$ compared with control group $(3.9 \pm 0.34 \mathrm{mEq} / \mathrm{L}, 1.98 \pm 0.18$ $\mathrm{mmol} / \mathrm{L}, \quad 128.3 \pm 12.71 \mathrm{mEq} / \mathrm{L})$ respectively. Administration of $\alpha$-tocopherol $(60 \mathrm{mg} / \mathrm{kg})$ in DOCA hypertensive rats (group DOCA+E) (c) 2011 by NWPII. All rights reserved. 
produced significant enhancement of both serum $\mathrm{K}^{+}(3.84 \pm 0.31 \mathrm{mEq} / \mathrm{L})$ and TAC $(1.56 \pm 0.13$ $\mathrm{mmol} / \mathrm{L})$ and a significant reduction in serum $\mathrm{Na}^{+}$ levels $(132.5 \pm 11.86 \mathrm{mEq} / \mathrm{L})$ compared with hypertensive non treated rats. In DOCA+E, TAC levels were still significantly $(\mathrm{P}<0.001)$ lowered and $\mathrm{Na}^{+}$still significantly higher while $\mathrm{K}+$ showed insignificant $(\mathrm{P}>0.05)$ changed compared with the control group. On the other hand, ACEI treatment in hypertensive rats (DOCA+ACEI group) produced significant increases in both serum $\mathrm{K}^{+}$ $(3.86 \pm 0.37 \mathrm{mEq} / \mathrm{L})$ and TAC $(1.1 \pm 0.09 \mathrm{mmol} / \mathrm{L})$ and significant reduction in serum $\mathrm{Na}^{+}$levels $(130.2 \pm 14.12 \mathrm{mEq} / \mathrm{L})$ compared with hypertensive non treated rats. While ACEI treated hypertensive rats showed significant reduction
$(\mathrm{P}<0.001)$ in TAC compared with both control and $\alpha$-tocopherol group; it showed insignificant $(\mathrm{P}>0.05)$ changes in serum $\mathrm{K}^{+}$and $\mathrm{Na}^{+}$compared with $\alpha$-tocopherol treated group. Concomitant treatment with both $\alpha$-tocopherol and ACEI in group DOCA+E+ACEI resulted in significant improvement in serum $\mathrm{Na}^{+}$and TAC compared with the DOCA hypertensive rats, $\alpha$-tocopherol and ACEI treated groups $(\mathrm{P}<0.001)$ and insignificant changed with the $(\mathrm{P}>0.05)$ control groups. Although serum $\mathrm{K}^{+}$showed significant improvement $(\mathrm{P}<0.001)$ in concomitant treated group compared with the DOCA group, it is insignificantly $(\mathrm{P}>0.05)$ changed compared with control, $\alpha$-tocopherol, ACEI treated groups [Table (1) and Figure (1)].
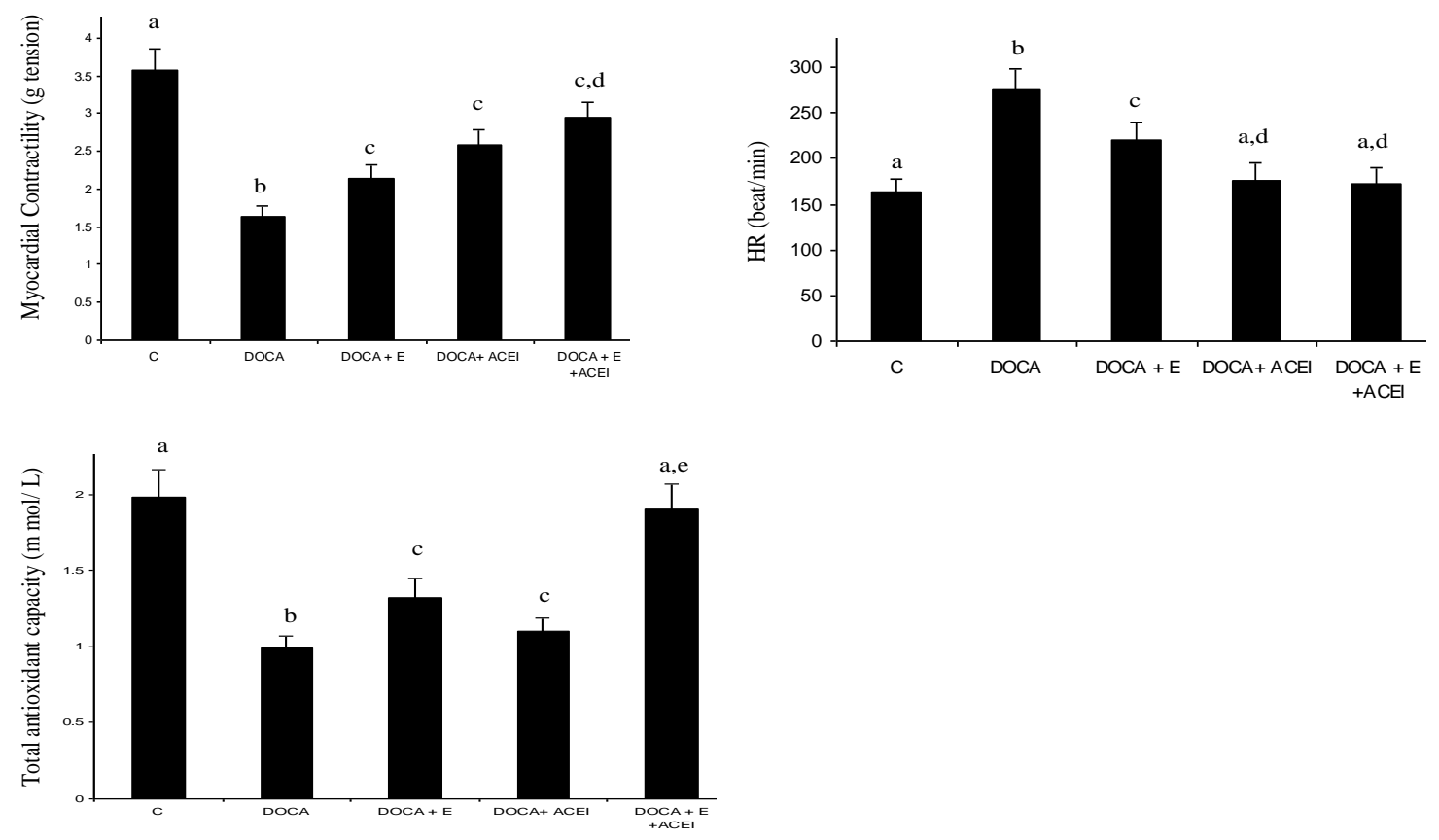

Figure 1. Effect of vitamin E and ACEI on Myocardial contractility (MC), Heart rate (HR) and Total antioxidant capacity (TAC) levels in different groups. C: Control group; DOCA: Hypertensive rats; : Hypertensive rats treated with vitamin E; DOCA+ACEI: Hypertensive rats treated with ACEI and DOCA+E+ACEI: Hypertensive rats treated with both vitamin $\mathrm{E}$ and ACEI.

Results are expressed as mean $\pm \mathrm{SD}(\mathrm{n}=8)$.

Groups with different letters are statistically significant

\subsection{Changes in DNA and RNA analysis in myocardial tissues}

Figure (2) showed a significant increases in the RNA and a significant decrease in DNA levels in DOCA group $(122.66 \pm 11.7$ m.w. in bp and $57.6 \pm 4.3 \mathrm{~m}$.w. in bp respectively) compared with control group $(36.5 \pm 3.4 \mathrm{~m}$.w. in bp and $202.5 \pm$ $22.5 \mathrm{~m}$.w. in bp respectively) ( $\mathrm{P}<0.001$ for both). 
$\alpha$-tocopherol treatment in DOCA rats produced a significant reduction $(\mathrm{p}<0.001)$ in RNA analysis $(100.74 \pm 10.4 \mathrm{~m} . \mathrm{w}$. in bp) and a significant elevation of DNA analysis $(98.6 \pm 6.9$ m.w. in bp) compared with DOCA group ( $\mathrm{P}<0.001$ for both). In DOCA hypertensive rats treated with ACEI, the RNA analyses was $81.8 \pm 7.15 \mathrm{~m}$.w. in bp, which was significantly lower while the DNA analyses was $160.3 \pm 15.2 \mathrm{~m}$.w. in bp which was significantly higher compared with DOCA group (P $<0.001$ for both). Treatment with ACEI in DOCA hypertensive rats produced a significant reduction in RNA analysis and a significant elevation in DNA analysis compared with values in $\alpha$-tocopherol treated DOCA hypertensive group. On the other hand, concomitant administration of both ACEI and $\alpha$-tocopherol in DOCA hypertensive rats resulted in a significant reduction (43.43 \pm 4.2 m.w. in bp) in RNA and a significant elevation of DNA analysis (200.75 \pm 20.46 m.w. in bp) compared with either DOCA $+\mathrm{E}$ or DOCA+ACEI treated groups $(\mathrm{P}<0.001$ for both).
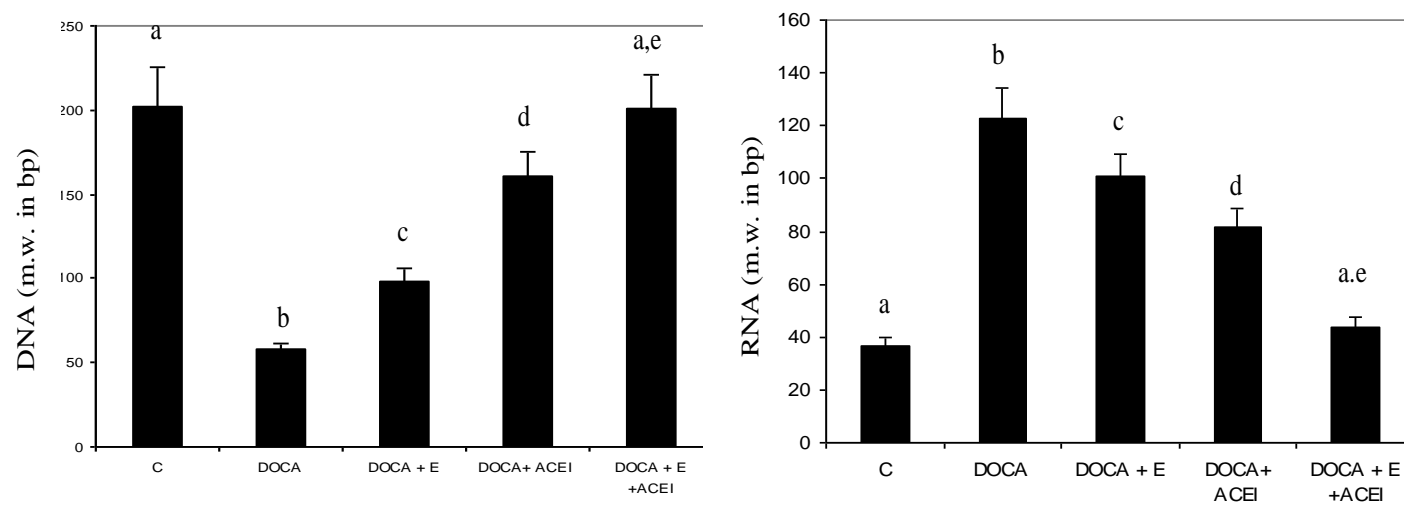

Figure 2 Effect of vitamin E and ACEI on DNA and RNA levels in different groups. C: Control group; DOCA: Hypertensive rats; DOCA+E: Hypertensive rats treated with vitamin E; DOCA+ACEI: Hypertensive rats treated with ACEI and DOCA+E+ACEI: Hypertensive rats treated with both vitamin E and ACEI.

Results are expressed as mean $\pm \mathrm{SD}(\mathrm{n}=8)$.

Groups with different letters are statistically significant

\section{Discussion}

Oxidative stress is one of the major determinants of endothelial dysfunction and cardiovascular disorders. It is hypothesized that, the imbalance between production and scavenging of superoxide anion increases oxidative stress and results in hypertension with subsequent cardiovascular nucleic acid changes [24].

In the present study, DOCA administration in rats produced significant increase in serum $\mathrm{Na}^{+}$, MSP, RVR, and RNA levels and a significant reduction in serum $\mathrm{K}^{+}$, TAC, MC and DNA levels compared with the control group. DOCA induced hypertension is a well known model of animal induced hypertension. The mechanism by which DOCA induces hypertension could be through Am. J. Biomed. Sci. 2011, 3(1), 57-68; doi: 10.5099/aj110100058 activation of $\mathrm{Na}^{+}-\mathrm{K}^{+}$pump leads to increase sodium retention and potassium excretion with subsequent increase total peripheral resistance and altered vascular functions [25]. It has been stated that, in DOCA hypertensive rats, the plasma TAC is decreased suggesting the oxidative stress role of DOCA hypertensive rat model [26]. Ma et al. [27] mentioned that DOCA induces hypertension may be due to increase ROS production and reduction of their scavenging processes. DOCA induced accumulation of hydroperoxide in renal medulla have been found to disturb the blood pressureregulating role of the kidney with a resultant severe hypertension [28]. Also, the reduction of bioactivity of NO and over-production of Endothelin-1 due to oxidative stress play a role in increasing renal vascular resistance and decrease (C) 2011 by NWPII. All rights reserved. 
renal blood flow [26]. The reduction in $\mathrm{MC}$ and enhancement of HR in DOCA hypertensive rats in our study may be due to prolonged increase in the preload by sodium and water retention. It was suggested that DOCA hypertensive rats developed cardiovascular remodeling as left ventricular hypertrophy, left ventricular inflammatory cell infiltration, increased interstitial collagen and increased passive diastolic stiffness which led to prolongation of the action potential duration, vascular dysfunction and finally impaired contractility [29]. High oxidative stress level in DOCA hypertensive rats results in an increased plasma matrix metalloproteinases leading to impair left ventricular contraction and elasticity. Furthermore, overproduction of ROS increases level of Gi proteins resulting in reduction in cAMP level which may be contribute to impair cardiac contractility [30]. In addition, Bouzeghrane et al. [31] have been found accumulation of fibrillin- 1 immunostaining between cardiac myocytes with formation of microscopic scars in the perivascular area of both ventricles led to bad contractility. Increased heart rate in DOCA hypertensive rats in our study may be due to renal sympathetic nerve over-activity [32].

In the present study, DOCA hypertensive rats showed a significant increase in RNA with a significant reduction in DNA of left ventricular tissue compared with normotensive rats. These results coincide with the study of Marcil et al. [33], who reported that the levels of $\mathrm{Gi}$ alpha- 2 and $\mathrm{Gi}$ alpha-3 mRNA were significantly enhanced in hearts from DOCA-salt treated rats. It was documented that free radicals are known to initiate apoptosis signaling pathways [34]. Apoptosis have been found in perivascular areas of the cardiac muscles of rats at 8 days and in scar areas at 16 days after DOCA-salt treatment [35]. Abnormal mechanical load seen in hypertension was found to induce heart cell apoptosis. ROS over-production increases the cardiac muscle $\mathrm{Ca}^{2+}$ level that could participate in the early stage of stretch-induced apoptosis with nuclear fragmentation [36]. Akishita et al. [37] reported that angiotensin-1 receptor signaling augments endothelial cells apoptosis in the process of oxidative stress-induced vascular injury.

Am. J. Biomed. Sci. 2011, 3(1), 57-68; doi: 10.5099/aj110100058
Administration of ACEI in DOCA hypertensive group in the present study produced a significant $(\mathrm{P}<0.001)$ reduction of serum $\mathrm{Na}^{+}, \mathrm{MSP}$, RVR and $\mathrm{HR}$ with a significant enhancement of serum $\mathrm{K}^{+}$, TAC, MC and RBV values. This was in agreement with Jia et al., [38], who reported that, in DOCA hypertensive rats, ACEI administration lowered SBP up to control levels which may be due to protection of the endothelial function by increasing NO production. Several other mechanisms could explain the blood pressure lowering effect of ACEI including marked reduction of serum angiotensin II level thereby; removing the vasoconstriction induced by this peptide on of coronary, renal and brain vessels [39]. Also, ACEI treatment in hypertension improves left ventricular systolic and diastolic functions due to improving fractional shortening, peak shortening rate and peak lengthening rate. ACEI enhances intracellular calcium handling and so improved excitation contraction coupling as seen in our study [40]. It has been reported that, ACEI treatment in hypertension improves renal blood flow leading to decrease progression of renal insufficiency caused hypertension due to direct inhibition of ACE activity in renal vessel [41].

On the other hand, hypertensive ACEI treated rats in the present study showed a significant increase $(\mathrm{P}<0.001)$ in DNA and a significant decrease $(\mathrm{P}<0.001)$ in RNA compared with DOCA hypertensive group. These results were coincided with Shimozawa et al. [42], who reported that, ACEI decreased the surface expression of protein and mRNA levels of intercellular and vascular adhesion molecule-1. ACEI therapy was associated with decreased Angiotensin II, myocardial collagen content, and myocardial stiffness [43]. It has been found that, ACEI reduce apoptosis by $54 \%$ of ischemia/reperfusion-induced cardiomyocyte apoptosis assessed by typical DNA laddering [44].

The present investigation showed that, treatment of DOCA hypertensive rats with oral $\alpha$ tocopherol for 6 weeks revealed a significant decrease $(\mathrm{P}<0.001)$ of serum $\mathrm{Na}^{+}, \mathrm{MSP}, \mathrm{RVR}$ and HR $(\mathrm{P}<0.001)$ with a significant increase in total antioxidant capacity $(\mathrm{P}<0.001)$, serum $\mathrm{K}^{+}$, TAC, RBV and MC $(\mathrm{P}<0.001)$ levels compared with hypertensive non-treated group. These data were in 
agreement with Newaz et al. [45], who mentioned that $\alpha$-tocopherol-treatment produced a significant reduction of blood pressure in DOCA hypertensive rats by scavenging the resultant harmful oxidants. A number of hypotheses have been suggested to explain the hypotensive effect of $\alpha$-tocopherol, such as inhibition of platelet adhesion, decrease of cardiac and vascular muscle cells proliferation with reduction of protein C-kinase activity [46]. Seifi et al., [28] reported that, oxidative stress impaired renal handling of some electrolytes leading to increase serum sodium and decreased serum potassium which was reversed by oral $\alpha$-tocopherol administration.

It has been reported that, $\alpha$-tocopherol supplementation improves left ventricular functions and significantly attenuates myocardial 8-iso-prostaglandin $\mathrm{F}_{2}-\alpha$ and oxidized glutathione accumulation [47]. $\alpha$-tocopherol improves endothelial function through different suggested mechanisms including; direct free radicalscavenging activity; regulation of NO synthase activity; regulation of enzymes such as NADPH oxidase that generate free radicals and regulation of antioxidant enzymes including SOD [48]. The influence of $\alpha$-tocopherol on the activity of certain genes is one of the most striking observations made in the field of $\alpha$-tocopherol research [49]. The expression of $\alpha$-tropomyosin may play a pivot role in the mechanism through which $\alpha$-tocopherol induced inhibition of smooth muscle cell proliferation. It have been found that $\alpha$-tocopherol mediated inhibition of CD36 scavenger receptor expression and the concomitant inhibition of oxidized LDL uptake into cells prevents foam cell formation and apoptosis in vivo [12].

The present study showed that, $\alpha$-tocopherol treatment in DOCA rats produced a significant reduction $(\mathrm{P}<0.001)$ in RNA and a significant increase $(\mathrm{P}<0.001)$ in DNA levels. It has been found that $\alpha$-tocopherol strongly but not completely reduces programmed cell death (apoptosis) and chemokines release suggesting other pathways different than its antioxidant activity [50]. Nicholson et al. [51] stated that, apoptosis is mediated by members of the caspase family of proteases and eventually causes the degradation of chromosomal DNA. Fortunately, $\alpha-$ tocopherol therapy plus septic challenge decreased caspase activity, abrogated cardiomyocyte secretion of inflammatory cytokines limiting their apoptosis in transplanted heart [52]. Moreover, Bansal and Jaswal [53] approved that; $\alpha$-tocopherol inhibits oxidative stress and apoptosis through inhibition of mitochondrial damage by oxidative stress that initiates chromatin fragmentation and apoptosis.

Concomitant administration of oral $\alpha$ tocopherol and ACEI in DOCA hypertensive rats revealed a significant improvement of all the previously measured parameters compared with DOCA hypertensive non-treated, ACEI treated and $\alpha$-tocopherol-treated groups. This improvement may be due to the improvement of endothelial function and serum electrolytes with ACEI [25], in addition to antioxidant, gene expression activity and hypolipidemic effect of $\alpha$-tocopherol [12]. Also both $\alpha$-tocopherol with ACEI treatment leads to enhance generation of NO by increased eNOS activity [48] with regulation of angiotensin II receptors [54]. This may explain the additive effect of concomitant administration of both agents.

\section{Conclusion}

From the present study, it seems that $\alpha$ tocopherol may be beneficial to hypertensive patients especially when combined with ordinary medications as ACEI, as it improved both chemical parameters and the cardiovascular nucleic acids state and structure; hence reduces the risks of cardiovascular complications. The combination of $\alpha$-tocopherol and ACEI administration dramatically improves the cardiovascular performance and nucleic acids changes in rats under stressful condition of DOCA hypertension than the use of each alone. This study may highlight on another mechanism through which $\alpha$-tocopherol may protect the cardiovascular system in hypertensive patients.

\section{References}

1. Zhu, H.Y.; Shi-Wen, W.S.; Liu, L.; Li, Y.; Chen, R.; Wang, L.; Holliman, C. A mitochondrial mutation A4401G is involved in the pathogenesis of left ventricular

C 2011 by NWPII. All rights reserved. 
hypertrophy in Chinese hypertensives, European Journal of Human Genetics, 2009, 17,172-178.

2. Sharma J.N. An Overview on Relation between the Bradykinin System and Hypertension and Diabetes, Am. J. Biomed. Sci., 2009, 1(3), 242-249.

3. Forte, P.; Copland, M.; Smith L.M. Basal nitric oxide synthesis in essential hypertension. Lancet, 1997, 349,105-110.

4. Orlov, S.N.; Thorin-Trescases, N.; Kotelevtsev, S.V.; Tremblay, J.; Hamet, P. Inversion of the intracellular $\mathrm{Na}^{+} / \mathrm{K}^{+}$ratio blocks apoptosis in vascular smooth muscle at a site upstream of caspase-3, J Biol. Chem., 1999, 274,16545-16552.

5. Lee, Y.L.; Kim, T.Y.; Hong, Y.M. Metalloproteinase-3 Genotype as a Predictor of Cardiovascular Risk in Hypertensive Adolescents, Korean Circ J., 2009, 39(8),32834.

6. Pepine, C.J.; Handberg, E.M. The vascular biology of hypertension and atherosclerosis and intervention with calcium antagonists and angiotensin-converting enzyme inhibitors. Clin Cardiol., 2001, 24(11), V1-5.

7. Bessa, S.S.; Ali, E. M.; Hamdy, S.M. The role of glutathione S- transferase M1 and T1 gene polymorphisms and oxidative stress-related parameters in Egyptian patients with essential hypertension, European Journal of Internal Medicine, 2009, 20,625-630.

8. Kaur, J and Sanyal, S. N. Oxidative Stress and Stress-signaling in Chemoprevention of Early Colon Cancer by Diclofenac, Am. J. Biomed. Sci., 2010, 2(1), 63-78.

9. Grassi, G. Phosducin - a candidate gene for stress dependent Hypertension, J. Clin. Invest., 2009, 119(12),3515-3518.

10. Szabo, C. Multiple pathways of peroxynitrite cytotoxicity, Toxicol Lett., 2003, 140 141,105-12.

11. Anna, C.; Pal, P.; Gabor, K.; Zoltan, U. Role of Oxidative and Nitrosative Stress, Longevity Genes and Poly(ADP-ribose) Polymerase in Cardiovascular Dysfunction Associated with Aging, Curr Vasc Pharmacol, 2005, 3(3), 285-291.

12. Brigelius-Flohé, R.; Kelly, F.J.; Salonen, J.T.; Neuzil, J.; Zingg, J.M.; Azzi, A. (2002): The European perspective on $\alpha$-tocopherol: current knowledge and future research, Am J Clin Nutr, 2002, 76(4),703-716.

Am. J. Biomed. Sci. 2011, 3(1), 57-68; doi: 10.5099/aj110100058
13. Franco, M.C.; Akamine, E.H.; Aparecida de Oliveira, M, Fortes, Z.B.; Tostes, R.C.; Carvalho, M.H.; Nigro, D. Vitamins C and E improve endothelial dysfunction in intrauterine-undernourished rats by decreasing vascular superoxide anion concentration, $J$ Cardiovasc Pharmacol, 2003, 42(2),211-217.

14. Jacques-Antoine, H.; Enar, C.; Gerard, W.; Gabriela, E.B.; Jean-rancois, A.; Esther, S.; Pascal, N.; Bernard, W.; Paolo, M. (1997): Hypertension increases connexin 43 in a tissue-specific manner, Circulation, 1997, 95,1007-1017.

15. Suzuki, S.; Katayama, Y.; Sugimoto, S.; Inamura, K.; Shimizu, J.; Soeda, T.; Nagazumi, A.; Terashi, A. Effect of long-term prior antihypertensive treatment on cerebral ischemia induced by bilateral common carotid artery ligation in SHRSR, No To Shinkei, 1986, 38(2), 155-161.

16. Wang, C.; Chao, L.; Chao, J. Direct gene delivery of human tissue kallikrein reduces blood pressure in SHR, $J$ Clin Invist., 1995,95,1710-1716.

17. James, W.L.; Martha, L.B.; Mary, A.; James, M.; Margaret, A.; Gali, R. Effects of Vanadate on renal hypertrophy and sorbitol accumulation in streptozotocin induced diabetes in rats, Res. Comm. Path. Pharmacol., 1991, 72,180-189.

18. Haywood, J.R.; Shaffer, R.A.; Fastenow, C. Regional blood flow measurements with pulsed Doppler flowmeter in rats. J. Physiol., 1981, 241,273-278

19. Toyokuni, S.; Tanaka, T.; Hattori, Y.; Nishiyama, Y.; Ochi, H.; Hiai, H.; Uchida, K.; Osawa, T. Quantitative immunohistochemical determination of 8-hydroxy-20deoxyguanosine by a monoclonal antibody N45.1: its application to ferric nitrilotriacetateinduced renal carcinogenesis model, Lab Invest., 1997, 76,365-374.

20. Ebuehi, O.A.; Bishop, S.A.; Anmuyiawa, O.O.; Akinwana, A.I.; Landengan, O.A. Biogenic amines metabolism and blood chemistry of psychiatric patients, Afr. J. Med. Sci. 2001, 30(4),269-273.

21. Rice-Evans, C.; Miller, N.J. Total antioxidant status in plasma and body fluids. Free Radical Research Group, UMDS-Guy's Hospital, 
London, United Kingdom, Methods Enzymol., 1994, 234,279-293.

22. Aljanabi, S.M.; Martinez, I. Universal and rapid salt-extraction of high quality genomic DNA for PCR-based techniques, Nucleic Acids Res., 1997, 25(22),4692-4693.

23. Hassab El-Nabi, S.E. Molecular studies on the relationship between apoptosis and DNA damage induced by dexamethasone and flummox in liver and spleen of rat and human lymphocytes culture, Histology \& Histochemistry, 2004, 45,175-202.

24. Zhu Z. Window Period for Oxidative Stress Attenuating Intervention (WPOS Theory), Am. J. Biomed. Sci., 2009, 1(3), 250-259.

25. Muto, S. Potassium Transport in the Mammalian Collecting Duct, Physiol Rev. 2001, 81: 85-116.

26. Manning, R.D.; Tian, N.; Meng, S. Oxidative stress and antioxidant treatment in hypertension and the associated renal damage, Am J Nephrol., 2005, (4),311-317.

27. Ma, X.L.; Gao, F.; Nelson, A.H.; Lopez, B.L.; Christopher, T.A.; Yue, T.L.; Barone F.C. Oxidative inactivation of nitric oxide and endothelial dysfunction in stroke-prone spontaneous hypertensive rats, J Pharmacol Exp Ther., 2001, 298(3),879-885.

28. Seifi, B.; Kadkhodaee, M.; Karimian, S.M.; Zahmatkesh, M.; Xu, J.; Soleimani, M. Evaluation of renal oxidative stress in the development of DOCA-salt induced hypertension and its renal damage, Clin Exp Hypertens., 2010, 32(2),90-97.

29. Chan, V.; Hoey, A.; Brown, L. Improved cardiovascular function with aminoguanidine in DOCA-salt hypertensive rats, $\mathrm{Br} J$ Pharmacol., 2006, 148(7),881-883.

30. Kramer, F.; Sandner, P.; Klein, M.; Krahn, T. Plasma concentrations of matrix metalloproteinase-2, tissue inhibitor of metalloproteinase-1 and osteopontin reflect severity of heart failure in DOCA-salt hypertensive rat. Biomarkers., 2008, 13(3), 270-81.

31. Bouzeghrane, F.; Reinhardt, D.P.; Reudelhuber, T.L.; Thibault, G. Enhanced expression of fibrillin-1, a constituent of the myocardial extracellular matrix in fibrosis, $A m$ J Physiol Heart Circ Physiol., 2005, 289(3),973-974.

32. Xu, H.; Fink, G.D.; Galligan, J.J. Nitric oxideindependent effects of tempol on sympathetic nerve activity and blood pressure in DOCAsalt rats. Am J Physiol Heart Circ Physiol, 2002, 283(3),885-892.

33. Marcil, J.; de Champlain, J.; AnandSrivastava, M.B. Overexpression of Giproteins precedes the development of DOCAsalt-induced hypertension: relationship with adenylyl cyclase, Cardiovasc Res., 1998, 39(2),492-505.

34. Afaq, S; Ali R. Immunogenicity of Nitric Oxide Modified Chromatin and Its Implications in Systemic Lupus Erythematosus, Am. J. Biomed. Sci., 2010, 2(2), 98-107.

35. Fujisawa, G.; Dilley, R.; Fullerton, M.J.; Funder, J.W. Experimental cardiac fibrosis: differential time course of responses to mineralocorticoid-salt administration. Endocrinology, 2001, (8),3625-3631.

36. Liao, X.D.; Tang, A.H.; Chen, Q.; Jin, H.J.; Wu, C.H.; Chen, L.Y.; Wang, S.Q. Role of $\mathrm{Ca}^{2+}$ signaling in initiation of stretch-induced apoptosis in neonatal heart cells. Biochem Biophys Res Commun. 2003, 17,310(2):405411.

37. Akishita, A.M.; Nagai, K.; Xi, H.; Yu, W.; Sudoh, N.; Watanabe, T.; Ohara-Imaizumi, M.; Nagamatsu, S.; Kozaki, K.; Horiuchi, M.; Toba, K. Renin-angiotensin system modulates oxidative stress-induced endothelial cell apoptosis in rats. Hypertension, 2005, 45(6), 1188-93.

38. Jia, Z.; Aoyagi, T.; Yang, T. mPGES-1 protects against DOCA-salt hypertension via inhibition of oxidative stress or stimulation of NO/cGMP, Hypertension, 2010, 55(2),539546.

39. Pines, A.; Fisman, E.Z. ACE Inhibition with moexipril: a review of potential effects beyond blood pressure control, Am $J$ Cardiovasc Drugs, 2003, 3(5),351-60.

40. Sumimoto, T.; Ochi, T.; Ito, T.; Joh, T.; Muneta, S.; Hiwada, K.; Both a calcium 
antagonist and ACE inhibitor reverse hypertrophy in hypertension but a calcium antagonist also depresses contractility, Cardiovasc Drugs Ther., 1997, 11(1),27-32.

41. Skov, K.; Madsen, J.K.; Hansen, H.E.; Zagato, L.; Frandsen, E.; Bianchi, G.; Mulvany, M.J. Renal haemodynamics are not related to genotypes in offspring of parents with essential hypertension, J Renin Angiotensin Aldosterone Syst. 2006, 7(1),47-55.

42. Shimozawa, M.; Naito, Y.; Manabe, H.; Uchiyama, K.; Katada, K.; Kuroda, M.; Nakabe, N.; Yoshida, N.; Yoshikawa, T. The inhibitory effect of alacepril, an angiotensinconverting enzyme inhibitor, on endothelial inflammatory response induced by oxysterol and TNF-alpha, Redox Rep., 2004, 9(6),354-9.

43. Klotz, S.; Danser, A.H.; Foronjy, R.F.; Oz, M.C.; Wang, J.; Mancini, D.; D'Armiento, J.; Burkhoff, D. The impact of angiotensinconverting enzyme inhibitor therapy on the extracellular collagen matrix during left ventricular assist device support in patients with end-stage heart failure, $J$ Am Coll Cardiol., 2007, 49(11),1166-1174.

44. Wang, L.X.; Ideishi, M.; Yahiro, E.; Urata, H.; Arakawa, K.; Saku, K. Mechanism of the cardioprotective effect of inhibition of the renin-angiotensin system on ischemia/reperfusion-induced myocardial injury, Hypertens Res., 2001, 24(2),179-187.

45. Newaz, M.A.; Nawal, N.N.; Rohaizan, C.H.; Muslim, N.; Gapor, A. alphaTocopherol increased nitric oxide synthase activity in blood vessels of spontaneously hypertensive rats. Am J Hypertens., 1999, 12(8 pt 1),839-844.

46. Bharrhan, S; Chopra, K; Rishi P. Vitamin E Supplementation Modulates Endotoxininduced Liver Damage in a Rat Model, Am. J. Biomed. Sci., 2010, 2(1), 51-62.

47. Hamblin, M.; Smith, H.M.; Hill, M.F. Dietary supplementation with $\alpha$-tocopherol ameliorates cardiac failure in type I diabetic cardiomyopathy by suppressing myocardial generation of 8-iso-prostaglandin F2alpha and oxidized glutathione. J Card Fail., 2007, 13(10),884-92.

48. Ülker, S.; McKeown, P.P.; Bayraktutan, U. Vitamins Reverse Endothelial Dysfunction Through Regulation of eNOS and NAD $(\mathrm{P}) \mathrm{H}$ Oxidase Activities. Hypertension, 2003, 41,534.

49. Azzi, A.; Boscoboinik, D.; Fazzio, A.; et al. RRR-alpha-tocopherol regulation of gene transcription in response to the cell oxidant status. Z Ernahrungswiss, 1998, 37,21-8.

50. Kerkeni, M.; Tnani, M.; Chuniaud, L.; Miled, A.; Maaroufi, K.; Trivin, F. Comparative study on in vitro effects of homocysteine thiolactone and homocysteine on HUVEC cells: evidence for a stronger proapoptotic and proinflammative homocysteine thiolactone, Mol Cell Biochem., 2006, 291(1-2) 119-126.

51. Nicholson, D.W.; All, A.; Thornberry, N.A.; Vaillancourt, J.P.; Diang, C.K.; Gallant, M.; Gareau, Y.; Griffin, P.R.; Labelle, M.; Lazebnik, Y.A.; Munday, N.A.; Raju, S.M.; Smulson, M.E.; Yamin, T.; Yu, V.L.; Miller, D.K. Identification and inhibition of ICE/CED-3 protease necessary for mammalian apoptosis, Nature, 1995, 376,37-43.

52. Nguyen, T.K.; Nilakantan, V.; Felix, C.C.; Khanna, A.K.; Pieper, G.M. Beneficial effect of alpha-tocopheryl succinate in rat cardiac transplants, J Heart Lung Transplant., 2006, 25(6), 707-715.

53. Bansal, $\quad$ M. P.; Jaswal, S. Hypercholesterolemia Induced Oxidative Stress Is Reduced in Rats with Diets Enriched with Supplement from Dunaliella salina Algae, Am. J. Biomed. Sci., 2009, 1(3), 196-204.

54. Vaughan, D.E. (2001): Angiotensin, fibrinolysis and vascular homeostasis. Am. J. Cardiol., 2001, 87, 8,18C-24C. 